\title{
Fluorescence Emission Spectrum of Elodea Leaves Exposed to Nanoparticles
}

\author{
A. M. Maharramov, I. S. Ahmadov, M. A. Ramazanov, S. Q. Aliyeva, V. N. Ramazanli \\ Baku State University, Baku, Azerbaijan \\ Email: ismet522002@yahoo.com
}

Received 29 August 2014; accepted 10 June 2015; published 16 June 2015

Copyright (C) 2015 by authors and Scientific Research Publishing Inc.

This work is licensed under the Creative Commons Attribution International License (CC BY). http://creativecommons.org/licenses/by/4.0/

(c) (i) Open Access

\section{Abstract}

The intensive use of engineered nanoparticles (NPs) in industrial, agricultural and household applications will very likely lead to the release of such materials into the environment, especially water ecosystems. Water plants are an integral part of ecosystems; hence their interaction with NPs is inevitable. It is important to understand the consequences of this interaction and assess its potential effects. There are different types of approaches for investigating the toxic effects of NPs on plants. Chlorophyll fluorescence (ChIF) is one of interesting biophysical methods for testing the effects NPs on plants in vivo. ChIF is a suitable technique and a very powerful tool for the in vivo studying of photochemical and non-photochemical processes within thylakoid membranes, chloroplasts, plant tissues, and whole plants. The present work reports the in vivo observation of chlorophyll a fluorescence quenching induced by the iron $\left(\mathrm{Fe}_{3} \mathrm{O}_{4}, \mathrm{Fe}_{2} \mathrm{O}_{3}\right)$ and aluminum oxide $\left(\mathrm{Al}_{2} \mathrm{O}_{3}\right)$ nanoparticles. Excitation and emission spectra of intact leaves of Elodea were acquired by fluorescence spectrophotometer (Cary Eclipse) at room temperature. It was shown that the intensity of the ChlF decreased in the solution of $\mathrm{Fe}_{3} \mathrm{O}_{4}$ and $\mathrm{Al}_{2} \mathrm{O}_{3}$ nanoparticles on the light. $\mathrm{Fe}_{2} \mathrm{O}_{3}$ affected slightly and the toxicity of nanoparticles depended on dose and exposure period. It was clear from these experiments that the given nanoparticles penetrated into the cell and might decrease the chlorophyll content of leaves.

\section{Keywords}

Chlorophyll, Nanoparticles, Fluorescence, Emission Spectra, Chlorophyll Content

\section{Introduction}

The intensive use of manufactured nanoparticles (NPs) in industrial and household applications will very likely lead to the release of such materials into the environment, especially water ecosystems. Today it is not possible 
to predict or evaluate the impact of nanoparticles on aquatic systems; however, ecotoxicological studies show that aquatic organisms, both plants and animals, may be affected by NPs toxicity. Assessing the risks of these NPs in the environment requires an understanding of their mobility, reactivity, ecotoxicity and persistency. Water plants are an integral part of ecosystems; hence their interaction with NPs is inevitable. It is important to understand the consequences of this interaction and assess its potential effects. The penetration, uptake and accumulation of NPs in plant cells and tissues are not well researched. Furthermore, the mechanism of the development of the physiological changes caused by the exposure of plants to NPs also remains unclear. Researchers still didn't find the specific mechanism of nanotoxicity, but it was clear that it would be closely related to the chemical composition, chemical structure, particle size, rate of exposure, concentration and surface area of the NPs.

Some information suggests that aquatic plants, especially those in freshwater environments, take up and biotransform metal contaminants in similar ways to terrestrial plants [1]. Over the last decade the studies are reported on the effects of NPs on seed germination and growth [2], modulate cellular functions [3], cell membrane leakage [4], on photochemical reactions of photosynthesis [5], mediated DNA damage [6], may increase lipid membrane peroxidation upon contact to cells due to the reactive oxygen species (ROS) [7], increase nitrate reductase activity and stimulated the antioxidant system [8].

There are different types of approaches for investigating the toxic effects of NPs on plants. ChlF is one of interesting biophysical methods for testing the effects NPs on plants in vivo. Under normal physiological conditions for photosynthesis the largest part of visible light absorbed by the photosynthetic pigments (chlorophyll, carotenoids) is used for photochemical fixation and conversion of inorganic $\mathrm{CO}_{2}$ into sugars and biomass, small part of this light energy re-emitted as heat (ca.15\% - 20\%) and as red chlorophyll fluorescence (1\% - 3\%). When the photosynthetic process is reduced due to environmental stress the fluorescence emission is changing. The red chlorophyll fluorescence emission spectra are characterized by two maxima in the 690 and $735 \mathrm{~nm}$ regions. The ratio of F690/F735 is inversely correlated to the chlorophyll content and can be used as a live determination method of the chlorophyll content [9] [10]. It can also be applied to detect short-term and long-term stress effect on plants [11]. The measure of fluorescence yield of chlorophyll ( $\mathrm{Chl} \mathrm{a)} \mathrm{is} \mathrm{a} \mathrm{sensitive} \mathrm{methodological} \mathrm{approach}$ for the evaluation of pollutants toxicity [12]. It is well known that when photosynthetic events related to biochemical or physiological processes are inhibited, the yield and kinetics of dissipated fluorescence are significantly changed [13]. Therefore, Chl a fluorescence can serve as a reliable, noninvasive indicator of photosynthetic processes in plants. The fluorometric approach can provide useful information concerning photosynthetic electron transport and energy dissipation processes associated with PS II and PS I activity. The quantification study cellular process is one key step towards a deeper understanding of molecular mechanisms of interactions nanoparticle with plants. One promising approach is based fluorescence techniques at sub cellular resolution, which offer both a highly sensitive and additionally specific tool for live cell studying. The present work reports in vivo observation of chlorophyll a fluorescence quenching induced by nanoparticles.

Materials and Methods. The study was performed on photosynthesizing cells of leaves of the higher water plants Canadian waterweed Elodea canadensis (Figure 1). Elodea canadensis have been exposed as biological targets to nano-engineered materials. This plant has well known electrophysiological characteristics and can easily be cultured and handled in the laboratory conditions. The plants of Elodea canadensis are selected for studies due to the following reasons: they represent one of key species of aquatic macrophytes with an extremely broad range; this species is used in previous studies of accumulation and phytotoxicity of chemical pollutants, which provide material for comparative analysis; this species has outstanding economical and ecological importance as one of aggressive introduced species with a strong potential for invasion into new aquatic bodies [14]. For these reasons, this species has been the focus of many experiments and research in the hopes of establishing a greater knowledge of growth habits, the true threat it causes, and possible prevention methods. Plants were cultured in a laboratory conditions in the aquarium. For the experiments, actively growing shoots with $2-3 \mathrm{~cm}$ long were excised and preincubated over days in the light or in the dark at the artificial pond water (APW) whose composition included $1.0 \mathrm{mM} \mathrm{NaCl}, 0.1 \mathrm{mM} \mathrm{KCI}$, and $0.1 \mathrm{mM} \mathrm{CaCl}_{2}$. The exposure of leaves in experimental solutions was last from 3 hours to 7 days. Fluorescence spectra of Elodea canadensis cells were recorded on a spectrophotometer (Cary Eclipse, Varian, Austrian) in a 90 configuration. The Cary Eclipse Spectrophotometer uses a Xenon flash lamp for superior sensitivity, high signal-to-noise, and fast kinetics. It measures the emission of light from samples in four modes. Scan completes for $3 \mathrm{~min}$ and speed of scan is $24,000 \mathrm{~mm} / \mathrm{in}$. Excitation and emission spectra of intact leaves are acquired between $200 \pm 900 \mathrm{~nm}$. The Cary Eclipse is the only spectrophotometer with room light immunity. 


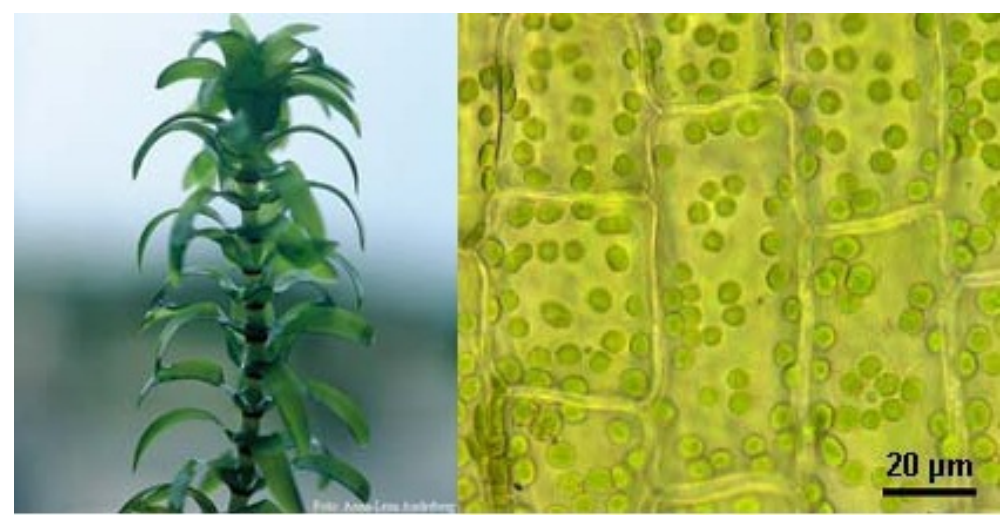

Figure 1. The leaves of Elodea canadensis have two-layer cell structure. The cells of the upper layer are large and visible by ordinary microscope and chloroplasts and their motion can clearly be seen.

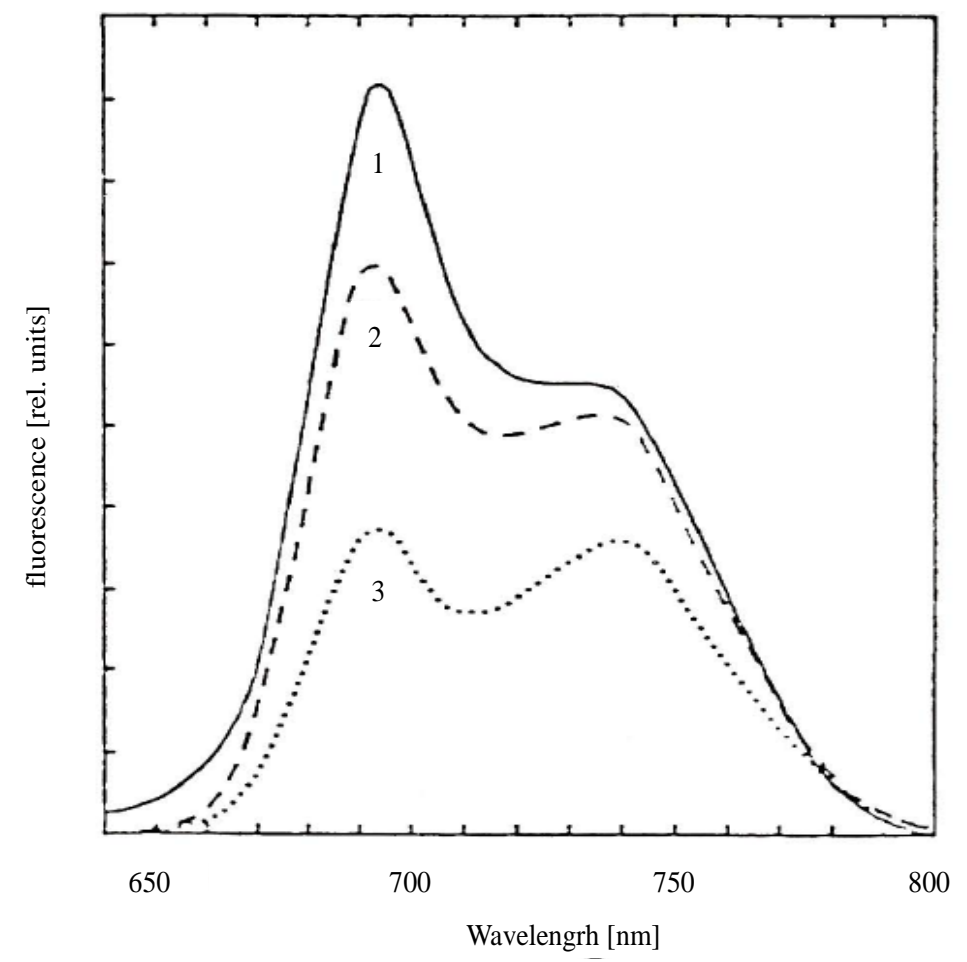

Figure 2. The ChlF emission spectra of beech leaves. The maximum of spectra near $690 \mathrm{~nm}$ is suppressed with increasing chlorophyll content due to a preferential re-absorption of the $690 \mathrm{~nm}$ fluorescence. 1) light green; 2) green; 3) dark green leaf. Excitation with blue light (470 nm) [15].

1.5 - $2 \mathrm{~cm}$ path-length leaves of elodea were used and measurements were made at $20^{\circ} \mathrm{C}$. Metal oxide nanoparticles $\left(\mathrm{Fe}_{3} \mathrm{O}_{4}, \mathrm{Fe}_{2} \mathrm{O}_{3}\right.$ and $\left.\mathrm{Al}_{2} \mathrm{O}_{3}\right)$ were dissolved in $\mathrm{APW}$ water. The leaves of elodea were exposure in solution of given nanoparticles in different time period in dark and light regime. Emission spectra were measured for an excitation wavelength corresponding to the maximum of the absorption spectrum. Excitation spectra were measured for an emission wavelength corresponding to the maximum of the emission spectrum. The disposition of the treatments on the experimental solutions is presented in Table 1.

Nanoparticles. For the study of impact of NPs there were used two types of iron nanoparticles- $-\mathrm{Fe}_{3} \mathrm{O}_{4}$ with a particle size of $100 \mathrm{~nm}, \mathrm{Fe}_{2} \mathrm{O}_{3}$ with a particle size $8 \mathrm{~nm}$, Aluminum oxide nanoparticles with size of $40 \mathrm{~nm}$ and 100 $\mathrm{nm}$. Aluminum nanopowders were manufactured by LLC "APT" of Institute of Physics of Strength and Material 
Table 1. The disposition of the treatments on the experimental solutions.

\begin{tabular}{cccc}
\hline Treatment & $\mathbf{F e}_{3} \mathbf{O}_{4} \mathbf{N P s} 100 \mathrm{~nm}$ & $\mathbf{F e}_{2} \mathbf{O}_{3} \mathbf{N P s} 8 \mathrm{~nm}$ & $\mathbf{A l}_{2} \mathbf{O}_{3} \mathbf{N P s} 40 \mathrm{~nm}$ \\
\hline A(control) & $0 \mathrm{mkg} / \mathrm{ml}$ & $0 \mathrm{mkg} / \mathrm{ml}$ & $0 \mathrm{mkg} / \mathrm{ml}$ \\
B (in light) & $1 \mathrm{mkg} / \mathrm{ml}$ & $1 \mathrm{mkg} / \mathrm{ml}$ & $1 \mathrm{mkg} / \mathrm{ml}$ \\
C (in dark) & $1 \mathrm{mkg} / \mathrm{ml}$ & $1 \mathrm{mkg} / \mathrm{ml}$ & $1 \mathrm{mkg} / \mathrm{ml}$ \\
\hline
\end{tabular}

Sciences (Tomsk, Russia). The $\mathrm{pH}$ was adjusted using either sodium hydroxide or sulphuric acid. For each nanomaterial, a stock solution of $1 \mu \mathrm{g} / \mathrm{ml}$ particle in culture medium without any additive was prepared, vortex at maximum speed for 1 minute and bath-sonicated for 10 minutes.

\section{Results of Experiments}

The in vivo chlorophyll fluorescence (ChlF) spectra of plant leaves shows two fluorescence maxima at room temperature, one in the red region at $685 \mathrm{~nm}$ emitted by PS II and other in the far-red region at $720-740 \mathrm{~nm}$ emitted by PS I. At higher chlorophyll concentrations, ChlF is mainly detected in the range of $720-740 \mathrm{~nm}$. But the re-absorption of the emitted red fluorescence by the chlorophyll in PS II results in a strong fluorescence emission band at $685 \mathrm{~nm}$ (Figure 2). The experiments show that ratio F690/F735 is inversely correlated to the chlorophyll content (curvilinear relationship), the shape of the peaks of the ChlF emission spectra changes with increasing chlorophyll content and can be used as a non-destructive determination method of the chlorophyll content [9] [10] [15] [16]. It can also be applied to detect short-term and long-term stress effects on plants. Under short-term and low stress conditions photosynthesis declines, without yet affecting the chlorophyll content and ratio F690/F735 rises by about 20\% to 30\%. Under long-term stress conditions photosynthesis may in part recover (due to adaptation and regeneration mechanisms), whereas the chlorophyll content declines and is maintained at a much lower level. This then causes a 1.5 to 4-fold increase in the fluorescence ratio F690/F735 [16]. Therefore the ChlF ratio F690/F735 appears to be a very suitable stress indicator, which can also be applied in stress detection of water plants. Because ChlF is connected to photosynthesis so it can be proposed for monitoring of uptake of nanoparticles into the cells and impact of on the pigments content of plants. For the detection effects of $\mathrm{Fe}_{3} \mathrm{O}_{4}, \mathrm{Fe}_{2} \mathrm{O}_{3}$ and $\mathrm{Al}_{2} \mathrm{O}_{3} \mathrm{NPs}$ on the photosynthesis, through chlorophyll content was measured the intensity of chlorophyll fluorescence emission maxima of elodea leaves which were exposure in different time period in light and dark regimes. First experiments show that the ChlF emission spectra of elodea leaves which are cultivated in normal condition are characterized by two maxima in the 686 and $733 \mathrm{~nm}$. The fluorescence intensity at $686 \mathrm{~nm}$ is much higher than at $733 \mathrm{~nm}$ as presented in Figure 3 (spectra 2). In the normal conditions the ChlF ratio F690/F735 was 1.27. The fluorescence quenching in elodea leaves submitted to the nanoparticle treatment was capable of detecting interactions between nanoparticles and plant cells. In experiments excitation wavelengths were taken $670 \mathrm{~nm}$. The emission wavelengths in this case was $685 \mathrm{~nm}$ or $686 \mathrm{~nm}$. There was the $733 \mathrm{~nm}$ emission peak, but this was insignificantly. We compared only first peak of 686 nm (Figure 3). In next experiments elodea leaves were broken and was cultivated in APW, in distilled water and in solution of $\mathrm{Fe}_{3} \mathrm{O}_{4}, \mathrm{Fe}_{2} \mathrm{O}_{3}$ nanoparticles. Nanoparticles were dissolved in distilled water. The results of these experiments suggested that nanoparticles $\mathrm{Fe}_{3} \mathrm{O}_{4}, \mathrm{Fe}_{2} \mathrm{O}_{3}$ were taken up and therefore bioavailable to elodea leaves. Fluorescence emission spectra and the ChlF ratio F690/F735 of elodea leaves which were exposed of 7 days in nanoparticles solutions in light is shown in Figure 4 and Table 2. The results of these experiments show that iron nanoparticles enter the cell and reduces intensity of first peak (686 nm) of emission spectra (Figure 4, spectra 4) with compared fluorescence emission peak of leaves from distilled water (Figure 4, spectra 2) and from aquarium (Figure 4, spectra 1). However, the intensity of fluorescence emission spectra of elodea leaves which were exposed for 7 days in Fe2O3 NPs on light does not differ from normal leaves (Figure 4, spectra 3). But the ChlF ratio F690/F735 leaves which was exposure in $\mathrm{Fe}_{2} \mathrm{O}_{3}$ nanoparticles is about $88 \%$ more than leaves taken from aquarium.

The same kind of experiments was carried out with leaves which were exposure in dark regime. The fluorescence emission spectra and the ChlF ratio F690/F735 of such leaves was shown in Figure 5 and Table 3. In this case the intensity of the fluorescence emission spectra also decreases in leaves from the $\mathrm{Fe}_{3} \mathrm{O}_{4}$ nanoparticles (Figure 5, spectra 3). But the intensity of the first peak $(686 \mathrm{~nm})$ of fluorescence emission spectra of leaves from $\mathrm{Fe}_{2} \mathrm{O}_{3}$ nanoparticles no so different from normal leaves (Figure 5, spectra 2). But the ChlF ratio F690/ 


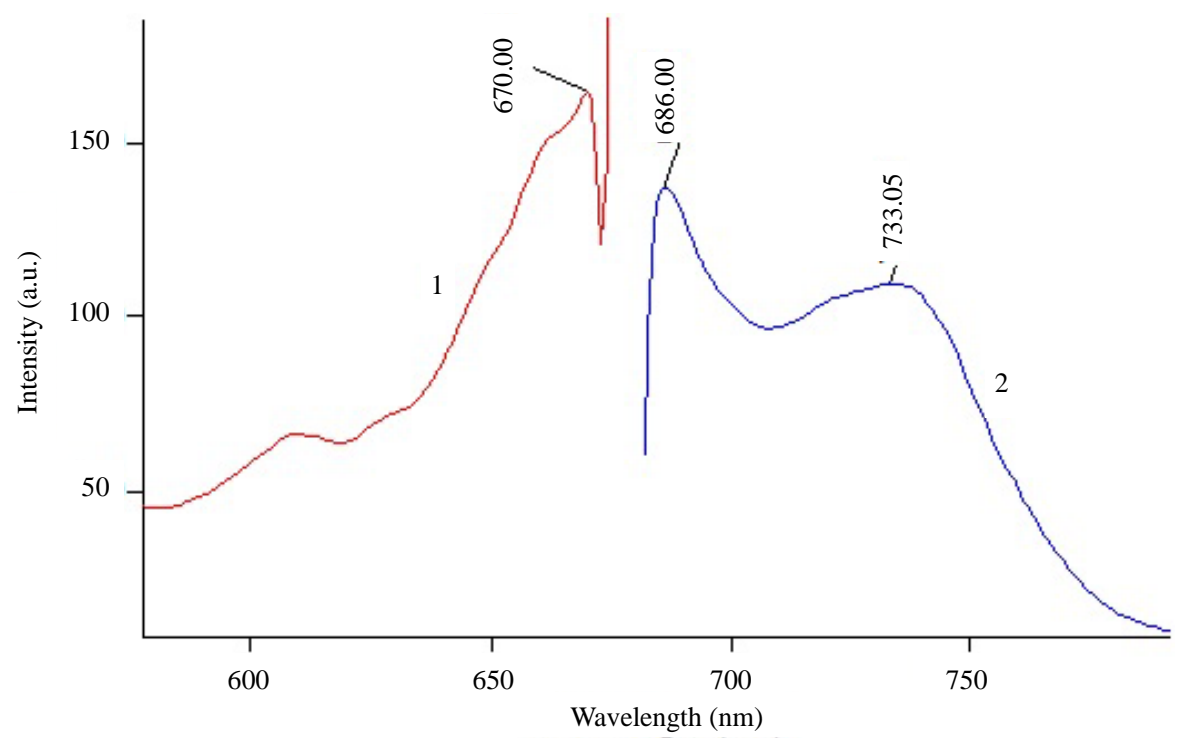

Figure 3. Fluorescence- excitation (1) and emission (2) spectra of Elodea leaves which was cultivated in normal conditions in aquarium.

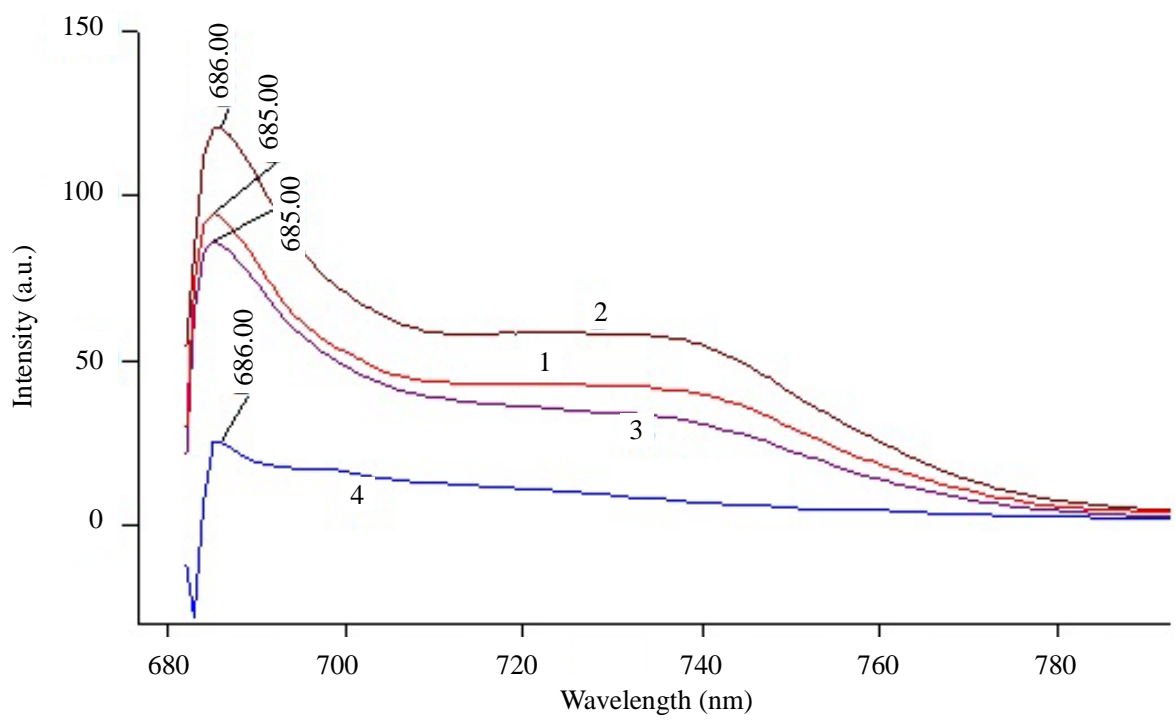

Figure 4. Fluorescence emission spectra of Elodea leaves which were exposed of 7 days in nanoparticles solutions and in normal conditions on light: 1) from aquarium; 2) from distilled water; 3) from $\mathrm{Fe}_{2} \mathrm{O}_{3}$ nanoparticles; 4) from $\mathrm{Fe}_{3} \mathrm{O}_{4}$ nanoparticles. The excitation wavelength was $670 \mathrm{~nm}$.

Table 2. The change of the ChlF ratio F690/F735 during 7 days exposure of leaves by nanoparticles on light. The excitation wavelength was $670 \mathrm{~nm}$.

Treatment

1) from aquarium

2) from distilled water

3) from $\mathrm{Fe}_{2} \mathrm{O}_{3}$ nanoparticles

4) from $\mathrm{Fe}_{3} \mathrm{O}_{4}$ nanoparticles
ChIF ratio F690/F735

$1.875 \pm 0.015$

$1.846 \pm 0.012$

$2.125 \pm 0.016$

$2.083 \pm 0.018$ 


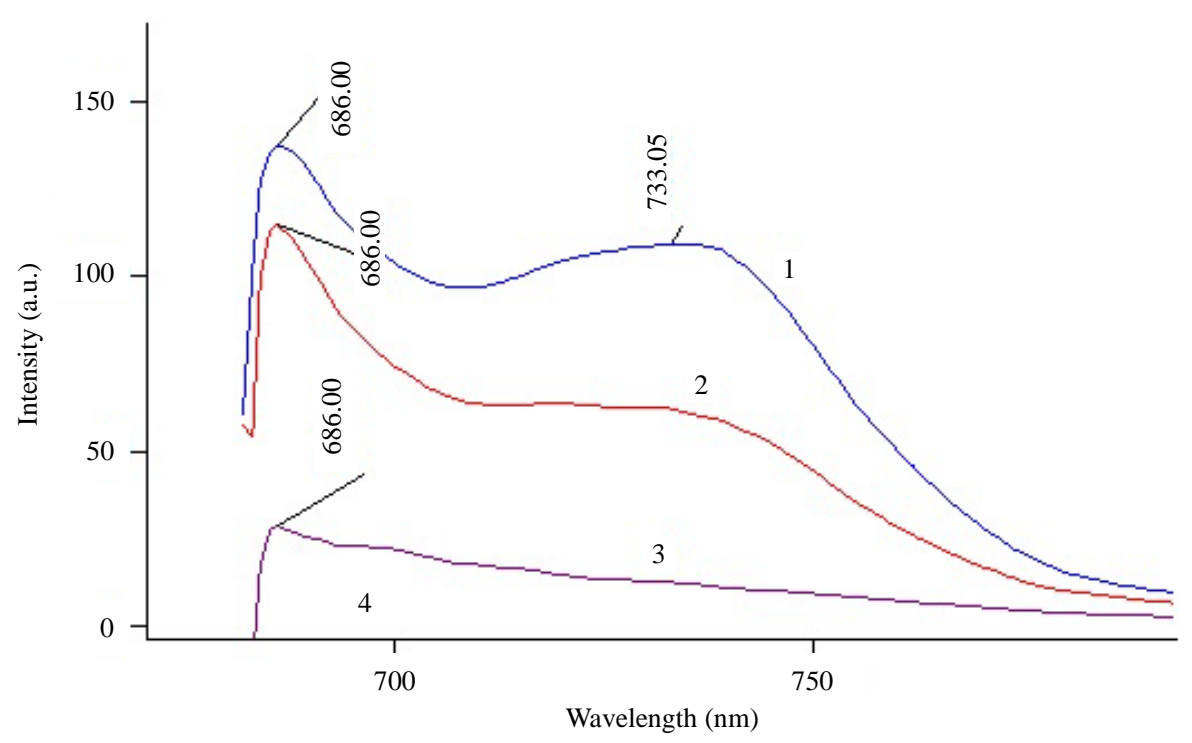

Figure 5. Fluorescence-emission spectra of elodea leaves which were exposed of 7 days in nanoparticles solutions in the dark: 1) from aquarium; 2) from $\mathrm{Fe}_{2} \mathrm{O}_{3}$ nanoparticles; 3) from $\mathrm{Fe}_{3} \mathrm{O}_{4}$ nanoparticles. The excitation wavelength was $670 \mathrm{~nm}$.

Table 3. The change of the ChlF ratio F690/F735 during 7 days exposure of leaves by nanoparticles in dark. The excitation wavelength was $670 \mathrm{~nm}$.

\begin{tabular}{lc}
\hline \multicolumn{1}{c}{ Treatment } & ChlF ratio F690/F735 \\
\hline 1) from aquarium & $1.272 \pm 0.015$ \\
2) from $\mathrm{Fe}_{2} \mathrm{O}_{3}$ nanoparticles & $1.917 \pm 0.012$ \\
3) from from $\mathrm{Fe}_{3} \mathrm{O}_{4}$ nanoparticles & $1.250 \pm 0.016$ \\
\hline
\end{tabular}

F735 leaves which was exposure in $\mathrm{Fe}_{2} \mathrm{O}_{3}$ nanoparticles in dark is about $67 \%$ more than leaves taken from aquarium. The ChlF ratio F690/F735 leaves which was exposure in $\mathrm{Fe}_{3} \mathrm{O}_{4}$ nanoparticles in dark is about $98 \%$ of leaves taken from aquarium (Table 3).

The interesting data was observed with elodea submitted to aluminum nanoparticles treatment. Thus the intensity of fluorescence emission spectra of elodea leaves which were exposed for 7 days in $\mathrm{Al}_{2} \mathrm{O}_{3}$ nanoparticles solutions in the dark (Figure 6, spectra 2) was 25\% higher than the intensity of spectra of leaves from $\mathrm{Al}_{2} \mathrm{O}_{3}$ nanoparticles in the light (Figure 6, spectra). The ChlF ratio F690/F735 of leaves from $\mathrm{Al}_{2} \mathrm{O}_{3}$ nanoparticles which were exposure in the dark $(1.531 \pm 0.015)$ was $78 \%$ more than the ChlF ratio F690/F735 of leaves from aquarium. But the ChlF ratio F690/F735 of leaves from $\mathrm{Al}_{2} \mathrm{O}_{3}$ nanoparticles which were exposure on light was 90\% more than the ChlF ratio F690/F735 of leaves from aquarium (Table 4).

\section{Discussion}

The intracellular effects and bioavailability of nanoparticles to plants are currently unknown completely. It is also unknown how nanoparticles are entered into the cell and what way they diffuse? There are a lot of works where have been reported regarding the uptake, translocation and localization of nanoparticles (less than $50 \mathrm{~nm}$ ) in plants [14] [17]-[20]. Results of our other experiments with EPR and confocal and two-photon microscopy studies point to a rapid accumulation of iron nanoparticles in leaves of elodea, i.e. to biomagnifications [21]. The results of experiments of Falco et al. [22] suggested that gold nanoparticles were able to translocation and accumulation in the soybean plants after seed inoculation. In vivo observation of chlorophyll a fluorescence quenching may be induced by gold nanoparticle. There are data about statistically significant diminution of chlorophylls and carotene levels in sunflower seedlings during exposing them in magnetic nanoparticles of $\mathrm{Fe}_{3} \mathrm{O}_{4}$. But with general slight effect on the photosynthesis global indicator-the chlorophyll ratio [23]. Comparative studies of effect of 


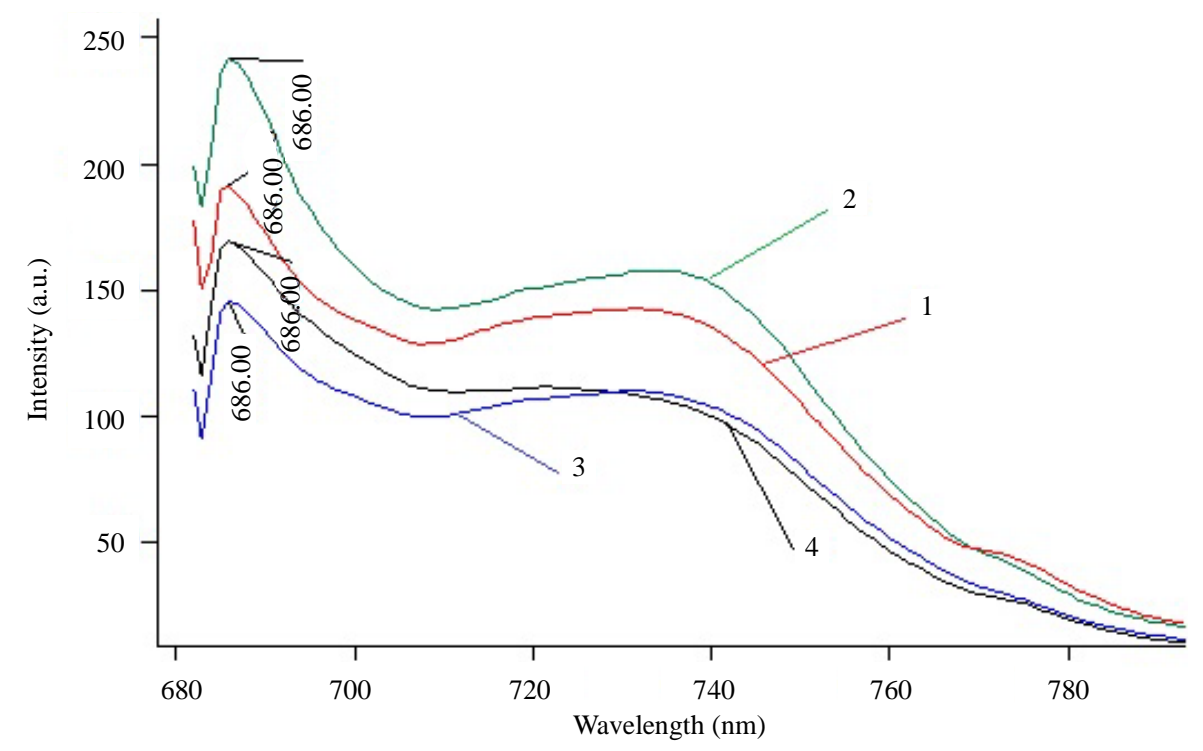

Figure 6. Fluorescence- emission spectra of elodea leaves which were exposed of 7 days in $\mathrm{Al}_{2} \mathrm{O}_{3}$ nanoparticles solutions: 1) from aquarium; 2) from $\mathrm{Al}_{2} \mathrm{O}_{3}$ nanoparticles (in the dark); 3) from $\mathrm{Al}_{2} \mathrm{O}_{3}$ nanoparticles (in the light); 4) from distiller water. The excitation wavelength was $670 \mathrm{~nm}$.

Table 4. The change of the ChlF ratio F690/F735 during 7 days exposure of leaves by $\mathrm{Al}_{2} \mathrm{O}_{3}$ nanoparticles. The excitation wavelength was $670 \mathrm{~nm}$.

\begin{tabular}{lc}
\hline \multicolumn{1}{c}{ Treatment } & ChlF ratio F690/F735 \\
\hline 1) from aquarium & $1.188 \pm 0.012$ \\
2) from $\mathrm{Al}_{2} \mathrm{O}_{3}$ nanoparticles (in the dark) & $1.531 \pm 0.015$ \\
3) from $\mathrm{Al}_{2} \mathrm{O}_{3}$ nanoparticles (on the light) & $1.318 \pm 0.013$ \\
4) from distiller water & $1.501 \pm 0.014$ \\
\hline
\end{tabular}

silver nanoparticles (AgNPs) and silver ions $\left(\mathrm{AgNO}_{3}\right)$ have showed the significantly diminution nitrate-nitrogen content, chlorophyll a (Chl a) content, chlorophyll a/b (Chl a/b), and chlorophyll fluorescence (Fv/Fm) in plant tissue in both case [24]. Exposure of algal thalli to increase concentrations of silver nanoparticles resulted in progressive depletion in algal chlorophyll content [25]. Relatively small volume fraction of magnetic fluid solutions of iron nanoparticles caused to increase the level of chlorophyll a (up to 38\%) in the Zea mays plantlets. All volume fractions of magnetic fluid solutions analyzed may have severe disruptive effects such as the ratio chlorophyll a/chlorophyll b (about 50\% decreasing) [26]. Results of our experiments with Chlorophyll fluorescence allow us to support idea about possibility uptake, translocation and localization NPs into plant cells. Our results also suggested that nanoparticles of iron and aluminum were able to translocation and accumulate in the elodea plants after exposition on these nanoparticles.

The parameters of fluorescence emission spectra such as peak position, peak height, band width, and band indicate that the intensities of the ChlF are much affected by nanoparticles treatment. The intensity and shape of the ChlF emission spectrum of elodea leaves at room temperature are primarily dependent on the types, concentration and exposure time period of the nanoparticles. The variation in the ChlF intensity at $\mathrm{F}_{685}$ is markedly more different than the fluorescence intensity at $\mathrm{F}_{730}$. We obtained a significant change in the intensity of fluorescence peak of $\mathrm{F} 686$ of leaves after exposure in $\mathrm{Fe}_{3} \mathrm{O}_{4}$ nanoparticles. The intensity of this fluorescence peak of $\mathrm{F}_{686}$ decreases about $25 \%$ after nanoparticles exposure (Figure 4). In more cases the peak of $\mathrm{F}_{735}$ disappears. As stated above the ratio F690/F735 is inversely correlated to the chlorophyll content and can be used as a non-destructive determination method of the chlorophyll content [9] [10]. It is well known that when photosynthetic events related to biochemical or physiological processes are inhibited, the yield and kinetics of dissipated fluo- 
rescence are significantly changed [13]. Therefore, if the $\mathrm{Chl}$ a fluorescence is changing it suggests that $\mathrm{Fe}_{3} \mathrm{O}_{4}$ nanoparticles affect the photosynthetic process. The ratio F690/F735 in our experiment was $2.125 \pm 0.016$ for $\mathrm{Fe}_{2} \mathrm{O}_{3}$ nanoparticles and it was about 2-fold more than for control. The ratio F690/F735 in our experiment was $2.125 \pm 0.016$ for $\mathrm{Fe}_{2} \mathrm{O}_{3}$ nanoparticles and it was about 2-fold more than for control. The ratio F690/F735 for $\mathrm{Fe}_{3} \mathrm{O}_{4}$ was $2.083 \pm 0.018$ and was also more than for control (Table 2). These results suggest that the chlorophyll content of elodea leaf decreases after exposure iron oxide nanoparticles. The effect of $\mathrm{Fe}_{3} \mathrm{O}_{4}$ nanoparticles is greatly more on the light than in the dark. The ratio $\mathrm{F} 690 / \mathrm{F} 735$ for $\mathrm{Fe}_{3} \mathrm{O}_{4}$ in dark leaves was $1.250 \pm 0.016$ and it was comparable with control which was $1.272 \pm 0.015$ (Table 3). These results suggest that the chlorophyll content of elodea leaf has significantly no changes after NPs exposure in dark. The effect of $\mathrm{Fe}_{2} \mathrm{O}_{3}$ nanoparticles on the $\mathrm{Chl}$ a fluorescence is low versus $\mathrm{Fe}_{3} \mathrm{O}_{4}$ nanoparticles influence. It may be the result of unrelated action of these nanoparticles with photosynthetic process.

Exposure of elodea leaves to solution of $\mathrm{Al}_{2} \mathrm{O}_{3}$ nanoparticles resulted no strong changes in chlorophyll fluorescence. It was slightly decreasing after 7 days exposure. The ratio $\mathrm{F} 690 / \mathrm{F} 735$ for $\mathrm{Al}_{2} \mathrm{O}_{3}$ in dark leaves was $1.531 \pm 0.015$ and it was slightly more than control which was $1.188 \pm 0.012$ (Table 4). It is interesting that the ratio F690/F73 on light for $\mathrm{Al}_{2} \mathrm{O}_{3}$ nanoparticles is less than in dark. It may be the results of aluminum oxide nanoparticles that they degrade chlorophyll more in dark than in light. The effect of $\mathrm{Al}_{2} \mathrm{O}_{3}$ nanoparticles does not strongly depend on the light-dark regime. This suggests that effect of aluminum nanoparticles is not related with photosynthetic processes.

\section{Conclusion}

The intensities of the Chl fluorescence at short-wavelength red fluorescence (near $686 \mathrm{~nm}$ ) and long-wavelength far-red fluorescence (near $733 \mathrm{~nm}$ ) and the ratio of fluorescence intensities at 686 and $733 \mathrm{~nm}$ (F690/F735) depends upon the dose, type and exposure period of nanoparticles. So Chl a fluorescence can serve as a reliable, noninvasive indicator of photosynthetic processes in plants during impact of nanoparticles. The results of these experiments allow concluding that there is possibility to use Chl fluorescence spectra to determine toxic effects of nanoparticles on plants.

\section{References}

[1] Rai, P.K. (2009) Heavy Metal Phytoremediation from Aquatic Ecosystems with Special Reference to Macrophytes. Critical Reviews in Environmental Science and Technology, 39, 697-753. http://dx.doi.org/10.1080/10643380801910058

[2] Stampoulis, D. Sinha, S.K. and White, J.C. (2009) Assay-Dependent Phytotoxicity of Nanoparticles to Plants. Environmental Science and Technology, 43, 9473-9479. http://dx.doi.org/10.1021/es901695c

[3] Arvizo, R.R., Miranda, O.R., Thompson, M.A., Pabelick, C.M., Bhattacharya, R., Robertson, J.D., Rotello, V.M., Prakash, Y.S. and Mukherjee, P. (2010) Effect of Nanoparticle Surface Charge at the Plasma Membrane and Beyond. Nano Letters, 10, 2543-2548. http://dx.doi.org/10.1021/nl101140t

[4] Leroueil, P.R., Berry, S.A., Duthie, K., Han, G., Rotello, V.M., McNerny, D.Q., Baker, J.R., Orr, B.G. and Holl, M.M.B. (2008) Wide Varieties of Cationic Nanoparticles Induce Defects in Supported Lipid Bilayers. Nano Letters, 8, 420-424. http://dx.doi.org/10.1021/nl0722929

[5] Atha, D.H., Wang, H.H., Petersen, E.J., Cleveland, D., Holbrook, D.R., Jaruga, P. et al. (2012) Copper Oxide Nanoparticle Mediated DNA Damage in Terrestrial Plant Models. Environmental Science and Technology, 46, 1819-1827. http://dx.doi.org/10.1021/es202660k

[6] Dewez, D. and Oukarroum, A. (2012) Silver Nanoparticles Toxicity Effect on Photosystem II Photochemistry of the Green Alga Chlamydomonas reinhardtii Treated in Light and Dark Conditions. Toxicological \& Environmental Chemistry, 94, 1536-1546.

[7] Santos, A.R., Miguel, A.S., Tomaz, L., Malhó, R., Maycock, C., Vaz Patto, M.C., Fevereiro, P. and Oliva, A. (2010) The Impact of CdSe/ZnS Quantum Dots in Cells of Medicago sativa in Suspension Culture. Journal of Nanobiotechnology, 8, 24. http://dx.doi.org/10.1186/1477-3155-8-24

[8] Lu, C.M., Zhang, C.Y., Wen, J.Q., Wu, G.R. and Tao, M.X. (2002) Research of the Effect of Nanometer Materials on Germination and Growth Enhancement of Glycine max and Its Mechanism. Soybean Science, 21, 168-171.

[9] Hak, R., Lichtenthaler, H.K. and Rinderle, U. (1990) Decrease of the Fluorescence Ratio F690/F730 during Greening and Development of Leaves. Radiation and Environmental Biophysics, 29, 329-336.

http://dx.doi.org/10.1007/BF01210413 
[10] Lichtenthaler, H.K., Hak, R. and Rinderle, U. (1990) The Chlorophyll Fluorescence Ratio F690/F730 in Leaves of Different Chlorophyll Content. Photosynthesis Research, 25, 295-298. http://dx.doi.org/10.1007/BF00033170

[11] Lichtenthaler, H.K., Stober, F. and Lang, M. (1992) The Nature of the Different Laser-Induced Fluorescence Signatures of Plants. EARSeL Advances in Remote Sensing, 1, No. 2-II.

[12] Juneau, P. and Popovic, R. (1999) Evidence for the Rapid Phytotoxicity and Environmental Stress Evaluation Using the PAM Fluorometric Method: Importance and Future Application. Ecotoxicology, 8, 449-455. http://dx.doi.org/10.1023/A:1008955819527

[13] Baker, N.R. (2008) Chlorophyll Fluorescence: A Probe of Photosynthesis in Vivo. Annual Review of Plant Biology, 59, 89-113. http://dx.doi.org/10.1146/annurev.arplant.59.032607.092759

[14] Johnson, M.E., Ostroumov, S.A., Tyson, J.F. and Xing, B. (2011) Study of the Interactions between Elodea canadensis and $\mathrm{CuO}$ Nanoparticles. Russian Journal of General Chemistry, 81, 2688-2693. http://dx.doi.org/10.1134/S107036321113010X

[15] Lichtenthaler, H.K. and Rinderle, U. (1988) The Role of Chlorophyll Fluorescence in the Detection of Stress Conditions in Plants. CRC Critical Reviews in Analytical Chemistry, 19, S29-S85. http://dx.doi.org/10.1080/15476510.1988.10401466

[16] Rinderle, U. and Lichtenthaler, H.K. (1988) The Chlorophyll Fluorescence Ratio F690/F735 as Possible Stress Indicator. In: Lichtenthaler, H.K. Applications of Chlorophyll Fluorescene in Photosynthesis Research, Stress Physiology, Hydrobiology and Remote Sensing, Springer Netherlands, City name, 189-196.

[17] Zhu, H., Han, J., Xiao, J.Q. and Jin, Y. (2008) Uptake, Translocation, and Accumulation of Manufactured Iron Oxide Nanoparticles by Pumpkin Plants. Journal of Environmental Monitoring, 10, 713-717. http://dx.doi.org/10.1039/b805998e

[18] Wilson, M.R., Lightbody, J.H., Donaldson, K., Sales, J. and Stone, V. (2002) Interactions between Ultrafine Particles and Transition Metals in Vivo and in Vitro. Toxicology and Applied Pharmacology, 184, 172-179. http://dx.doi.org/10.1006/taap.2002.9501

[19] Gonzalez-Melendi, P., Fernández-Pacheco, R., Coronado, M.J., et al. (2008) Nanoparticles as Smart Treatment Delivery Systems in Plants: Assessment of Different Techniques of Microscopy for Their Visualization in Plant Tissues. Annals of Botany, 101, 187-195. http://dx.doi.org/10.1093/aob/mcm283

[20] Corredor, E., Testillano, P.S., Coronado, M.-J., et al. (2009) Nanoparticle Penetration and Transport in Living Pumpkin Plants: In Situ Sub Cellular Identification. BMC Plant Biology, 9, 45. http://dx.doi.org/10.1186/1471-2229-9-45

[21] Spori, C.L., Prigent, G., Schaer, M., Crittin, M., Matus, P., Laroche, T., Sikora, B., Kaminska, I., Fronc, K., Elbaum, D., Digigow, R., Fink, A., Ahmadov, I., Khalilov, R., Ramazanov, M., Forró, L. and Sienkiewicz, A. (2014) Uptake and Biomagnification of Multifunctional Magnetic and NIR Sensitive Nanoparticles by NIR-Aquatic Plants: Electron Spin Resonance, Twophoton and Confocal Microscopy Studies. Proceedings of the Nano-Tera Annual Plenary Meeting, Lausanne, 19-20 May 2014, 82.

[22] Falco, W.F., Botero, E.R., Falcão, E.A., Santiag, E.F., Bagnato, V.S. and Caires, A.R.L. (2011) In Vivo Observation of Chlorophyll Fluorescence Quenching Induced by Gold Nanoparticles. Journal of Photochemistry and Photobiology A: Chemistry, 225, 65-71. http://dx.doi.org/10.1016/j.jphotochem.2011.09.027

[23] Ursache-Oprisan, M., Focanici, E., Creanga, D. and Caltun, O. (2011) Sunflower Chlorophyll Levels after Magnetic Nanoparticle Supply. African Journal of Biotechnology, 10, 7092-7098.

[24] Jiang, H.-S., Li, M., Chang, F.-Y., Li, W. and Yin, L.-Y. (2012) Physiological Analysis of Silver Nanoparticles and $\mathrm{AgNO}_{3}$ Toxicity to Spirodela polyrhiza. Environmental Toxicology and Chemistry, 31, 1880-1886. http://dx.doi.org/10.1002/etc.1899

[25] Dash, A., Singh, A.P., Chaudhary, B.R., Singh, S.K. and Dash, D. (2012) Effect of Silver Nanoparticles on Growth of Eukaryotic Green Algae. Nano-Micro Letters, 4, 158-165. http://dx.doi.org/10.1007/BF03353707

[26] Racuciu, M. (2012) Iron Oxide Nanoparticles Coated with $\beta$-Cyclodextrin Polluted of Zea mays Plantlets. http://www.pagepress.org/journals/index.php/nd/article/view/nd 